\title{
Subjective and Objective Assessments of Executive Functioning among Persons 10 years after Stroke Onset
}

Eva Elgh ${ }^{1}$ and Xiaolei $\mathrm{Hu}^{2}$ *

${ }^{1} \mathrm{PhD}$, Senior Neuropsychologist, Associate Professor, Department of Psychology

${ }^{2} \mathrm{MD}, \mathrm{PhD}$, Consultant Physiatrist, Department of Community Medicine and Rehabilitation, Umeå University, 901 87, Umeå, Sweden

*Corresponding Author: Xiaolei Hu, MD; PhD; Consultant physiatrist Department of Community Medicine and Rehabilitation Umeå University, 90185 Umeå, Sweden.

Received date: November 23, 2021; Accepted date: November 30, 2021; Published date: December 06, 2021

Citation: Eva Elgh and Xiaolei Hu (2021). Subjective and Objective Assessments of Executive Functioning among Persons 10 years after Stroke Onset. J. Neuroscience and Neurological Surgery. 10(1); DOI:10.31579/2578-8868/219

Copyrights: (C) 2021 Xiaolei Hu, This is an open-access article distributed under the terms of The Creative Commons Attribution License, which permits unrestricted use, distribution, and reproduction in any medium, provided the original author and source are credited

\section{Abstract}

Aim: This study aimed to investigate executive functioning (EF) among patients 10 years after stroke onset through comparing subjective patients' and informants' perceptions as well as objective neuropsychological assessments (NPAs).

Materials and Method: One month prior to the neuropsychological assessment, 36 patients and their informants completed the Behaviour Rating Inventory of Executive Function - Adult Version (Brief-A) around 10 years after stroke onset. The patients' EF was assessed with verbal fluency (FAS), backward Digit span backward and Trail making test (TMT)-B

Results: We found no significant differences between patient and informant ratings on EF on a group level, but more patients reported clinically significant executive dysfunctions $(T \geq 65)$ than their informants. Only poor to slight agreements were observed between the patient and informant ratings of the BRIEF-A. Digit span backward was the only executive test that demonstrated significant improvement of EF 10 years post-stroke in the cohort. Neither patient nor informant ratings on EF showed any significant association with objective EF test performance.

Conclusions: Mismatch patient-informant agreement on perceived executive dysfunction showed no clear association with EF test performance in this study. This may indicate the complexity of EF among persons with stroke at chronic phase.

Key words: executive function; stroke; cognition; patient-reported outcome measurements; neuropsychology assessment; caregivers

\section{Introduction}

Impairment of executive function (EF) is a common cognitive sequelae after stroke with profound negative effects on patients' activity of daily living and participation [1]. The prevalence of executive dysfunction after stroke varies from $19 \%$ to $75 \%$ depending on measurements and definition of EF used [2-6]. Recent studies have found that impairment of EF can be ameliorated after stroke by remedial and compensatory approaches [1] as well as daily activity [2] and occupation [7].

Many assessments have been used to measure EF due to its nature of complexity, including abilities such as planning, problem solving, switching, and inhibition and working memory. Performance-based cognitive tests, such as neuropsychological assessment (NPA), have been considered as golden standard for object evaluating cognitive function [811]. However, NPA do not necessarily fully reflect high-level mental functions, such as self-awareness, self-monitoring, planning and decisionmaking, in the daily living [10-12]. Some patient-reported outcome measurement (PROM) have been served as subjective assessments on these high-level mental functions, such as Behaviour Rating Inventory of Executive Function - Adult Version (BRIEF-A) [13]. The BRIEF-A is a widely used PROM on evaluating EF among elderly and persons with various acquired brain injury, including stroke [12,14-16]. The BRIEF-A consisting of both self- and informant form measures EF in daily living, which may provide a strong extension of standardized NPA [13].

However, patient- and informant report of EF has been less explored among stroke patients. Even less is known about the associations between 
patient- and informant reporting as well as their relations to EF data assessed by NPA among persons with stroke at chronic phase. This study aimed to investigate EFs among patients at 10-year after stroke onset through comparing subjective patients' and informants' perceptions of cognitive dysfunctions assessed by BRIEF-A as well as objective cognitive dysfunctions examined by NPA.

\section{Materials and Method}

\section{Study design and procedure}

Data of this study were collected in a single-centre prospective, longitudinal cohort study of stroke survivors with three consecutive follow-ups over a 10-year period after a first-ever stroke. The cognitive functions of stroke survivors were assessed prospectively at 10-year follow-up, then compared retrospectively with data collected 1 week after and 7 months after stroke before the study was planned [2,17]. The study was conducted at a Department of Neuro-Rehabilitation, University Hospital of Umeå. Ethical approval was obtained from the regional Ethical Review Board in Umeå, Sweden, D-nr 2015/144-31.

All young (18 to 65 years) patients who had suffered a first-ever stroke between January 2004 and December 2007 and undergone neuropsychological assessment (NPA) within the first year after stroke were contacted. Participants were informed about the study and provided with written consent forms via letter, and research staff made contact via telephone with all eligible patients in order to improve the recruitment rate. Patients with severe dementia, severe aphasia, severe comorbidity, recurrence of stroke or transient ischemic attack, or other physical or psychiatric disease after first-ever stroke, along with those who were not community-dwelling, were excluded [2]. After a thorough recruitment process taking place from 2015-2016, 49 of the total 102 first-ever young stroke patients with acute NPAs declined, and 15 others were excluded for a variety of reasons. In this study, two of 38 participants were excluded because of missing values in BRIEF-A. Seven participants lived alone without relative. Only 26 informants completed BRIEF-A without missing values. All were native Swedish citizens. The 38 participants provided their written informed consent to participant the study and assessed by NPAs. Baseline data were collected from the Riksstroke registry and from patients' medical records.

Behaviour Rating Inventory of Executive Function - Adult Version (BRIEF-A)

For subjective assessment of executive functioning, both participants and informants completed the BRIEF-A one month prior to the scheduled appointment for NPA.

BRIEF-A measure executive functions in daily living through self- and informant assessment [13]. The BRIEF-A consists of 75 items that measure different aspects of EF in the real-life situation. Answers are given on three options (i.e. never a problem $=1$, sometime a problem $=2$ and often a problem $=3$ ). Three index score were derived: 1 ) Behavioural Regulation (BRI) refers to the ability to control behaviours and emotions, consisting of subscale inhibit, shift, emotional control and self-monitor; 2) Metacognition (MI) refers to the ability to maintain attention and the ability to solve problems, consisting of subscale initiate, working memory, plan/organize, task-monitor and organization of material; 3) Global Executive Composite (GEC) is a summary scale for all subscales. The American standards were used to convert raw points into T-points [13]. Higher T scores indicate higher degree of executive dysfunction. T scores at and above 65 are considered as clinically significant impairments on EF [13].

In order to objective assess patients' executive function, three neuropsychological assessments were used in the current study and described below.

\section{Verbal fluency}

Phonemic fluency (FAS) is included in the executive test battery DelisKaplan Executive Function System (D-KEFS). The battery is standardized for individuals between the ages of 8 and 89 [8]. In this study, the patients were asked to say as many words as possible starting with a certain letter (F, A and S) for 60 seconds to measure the ability to orally produce words [8].

\section{Digit Span}

Digit Span from Wechsler Adult Intelligence Scale (WAIS) -IV was used to assess the working memory's number storage capacity. Notably, WAIS-R and WAIS-III was replaced by WAIS-IV at 10-year follow-up due to practical reason. Previous validation studies have shown that WAIS-IV have the same construction as WAIS-III/R [18] with very high correlation between subscales $(r=.82-94)$ [9]. Swedish norms for WAISIV were used as control [9].

Trail making test (TMT) - B

TMT-B intends to measure the executive function mental flexibility, i.e. the ability to switch between different stimuli under time pressure. An upper time limit was used (190 seconds) [19].

Data presentation and statistical analysis

Demographic characteristics are presented as Mean $\pm \mathrm{SD}$, number with/without number of cases $(\%)$ or median $(25 \%-75 \%$ interquartile ranges (IQR)) as appropriate.

Data from Brief-A were analysed using Wilcoxon matched-pairs signed rank test. The Cohen's kappa coefficient was used to measure the agreement between the patient and informant rating of the BRIEF-A $(0=$ poor agreement, $0.2=$ slight agreement, $0.4=$ fair agreement, $0.6=$ moderate agreement, $0.8=$ substantial agreement and $1.0=$ almost perfect agreement) [20].

The NPA at the early stage were presented at two time-points, i.e. one week and seven months with some missing values. Instead of ANOVA, Kruskal-Wallis test was chosen for nonparametric multiple comparisons between three time-points because of the relatively small sample size. Each $\mathrm{p}$ value was adjusted to account for multiple comparisons with Dunn's multiple comparisons test.

The level of associations between BRIEF-A and neuropsychological data were explored by using Spearman correlation coefficients. The statistical analyses were performed by using the software product GraphPad Prism, version 6.0 or IBM SPSS as appropriate. P value $<0.05$ was considered as significant.

\section{Results}

\section{Demographic and medical characteristics}

Demographic and medical characteristics of the participants at 10-year follow-up after stroke onset are presented in Table 1. 


\begin{tabular}{|l|c|}
\hline Age (mean \pm SD) & $63.8 \pm 10.6$ \\
\hline Gender (Men/Women) & $19 / 19$ \\
\hline $\begin{array}{l}\text { Residential status } \\
\text { (Live alone/live with somebody/unknown) }\end{array}$ & $7 / 30 / 1$ \\
\hline Stroke sub-type (number of case (\%)) & \\
\hline Ischemia & $30(79 \%)$ \\
\hline Haemorrhage & $6(16 \%)$ \\
\hline Unknown & $2(5 \%)$ \\
\hline Education (number of case (\%)) & $19(50 \%)$ \\
\hline 9 -12 years & $17(45 \%)$ \\
\hline$>12$ years & $2(5 \%)$ \\
\hline Unknown & $1(0-2)$ \\
\hline Modified Rankin Scale (Median (IQR)) & $10.5 \pm 0.9$ \\
\hline Years between follow-up and stroke onset (mean \pm SD) & \\
\hline
\end{tabular}

Table 1: Demographic and medical characteristics of the participants at 10-year follow-up after stroke onset

The mean age of participants was 63.8 (SD 10.6) with $50 \%$ female participants. Most of the participants ( $\mathrm{n}=34,34 / 37,92 \%)$ had no or only slight disability $(\mathrm{mRS}=0-2)$. Ischemia was the dominate stroke sub-type (79\%). Almost half of the participants $(n=17,17 / 37,46 \%)$ had more than 12 years education. The more detail characteristics of the participants have been described in the previous studies $[2,17]$.

Comparison of patient and informant rating on the BRIEF-A

Descriptive data from patient and informant ratings of the BRIEF-A were presented in Table 2.

\begin{tabular}{|c|c|c|c|c|c|c|}
\hline \multirow[t]{2}{*}{ Executive functions } & \multicolumn{2}{|c|}{ Patient } & \multicolumn{2}{|c|}{ Informant } & \multirow[t]{2}{*}{ p-value } & \multirow[t]{2}{*}{$\mathbf{k}$} \\
\hline & $\begin{array}{l}\text { T-score } \\
\text { Median (IQR) }\end{array}$ & $\%(\mathrm{~T}>65)$ & $\begin{array}{l}\text { T-score } \\
\text { Median (IQR) }\end{array}$ & $\%(\mathrm{~T}>65)$ & & \\
\hline Global Executive Composite & $49(44-58)$ & 17 & $49(42-53.3)$ & 8 & ns & 0.01 \\
\hline Behavioural Regulation index & $48(44-56)$ & 9 & $47(41-55)$ & 7 & ns & 0.05 \\
\hline Inhibit & $47(41.8-52)$ & 6 & $44(41-51.5)$ & 7 & ns & -0.19 \\
\hline Shift & $48.5(44-57)$ & 11 & $44(40-54)$ & 7 & $\mathrm{~ns}$ & 0.08 \\
\hline Emotional control & $53(43-62)$ & 22 & $50(41-58)$ & 11 & ns & 0.04 \\
\hline Self-monitor & $40(38-51.8)$ & 6 & $47(40-54)$ & 7 & ns & -0.03 \\
\hline Metacognition Index & $49.5(43.3-59)$ & 11 & $47.5(42.5-53)$ & 8 & $\mathrm{~ns}$ & 0.08 \\
\hline Initiate & $54(44.5-60.5)$ & 19 & $48(42-57)$ & 11 & ns & 0.08 \\
\hline Working memory & $56(44-67)$ & 30 & $53(42-61)$ & 14 & $\mathrm{~ns}$ & -0.01 \\
\hline Plan/Organize & $50(44-59)$ & 16 & $47(42-52.5)$ & 8 & $\mathrm{~ns}$ & 0.08 \\
\hline Task Monitor & $48(38-58)$ & 11 & $47(42-57)$ & 4 & $\mathrm{~ns}$ & -0.18 \\
\hline Organization of materials & $44(39.5-53)$ & 3 & $43(40-49)$ & 0 & ns & -0.04 \\
\hline
\end{tabular}

$\%(T>65)$ : percentage of of the patients with T-score > 65 on BRIEF-A self-and informant report scales indicating clinically significant impairment on EF; ns: no significant difference on $T$-scores between patient and informant analysed by Wilcoxon matched-pairs signed rank test. $k$ : Cohen's kappa coefficient measuring the agreement between patient and informant ratings of the BRIEF-A.

\section{Table 2: Descriptive data from patient and informant ratings of the BRIEF-A.}

Neuropsychological data

Three NPA test data over 10-year follow-up are shown as median (25\%$75 \%$ IQR) in Figure 1. Compared to results at one-week post-stroke, no significant enhancements on working memory were observed at 7 months after stroke onset assessed by WAIS-Digit span [9]. However, striking
On a group level, there was no median score of any subscale or main indexes of the BRIEF-A over 65 points i.e. the level for clinically significant impairment; but more patients reported clinically significant executive dysfunctions $(T>65)$ than their informants did. However, the statistical analyses demonstrated no significant differences between patients and informants reporting on any of the subscales or main indexes on BRIEF-A. Similar medians of global executive function (GEC) were rated by patients and informants. A slightly higher score were observed on BRI and MI among patients, but no significant difference.

Cohen $\mathrm{k}$ statistics demonstrated poor to slight agreements between the patient and informant ratings of the BRIEF-A (Table 2). \begin{tabular}{|l|}
\hline \\
\hline \\
\hline 01 \\
\hline 05 \\
\hline .19 \\
\hline 08 \\
\hline 04 \\
\hline .03 \\
\hline 08 \\
\hline 08 \\
\hline .01 \\
\hline 08 \\
\hline .18 \\
\hline .04 \\
\hline
\end{tabular} 
A.

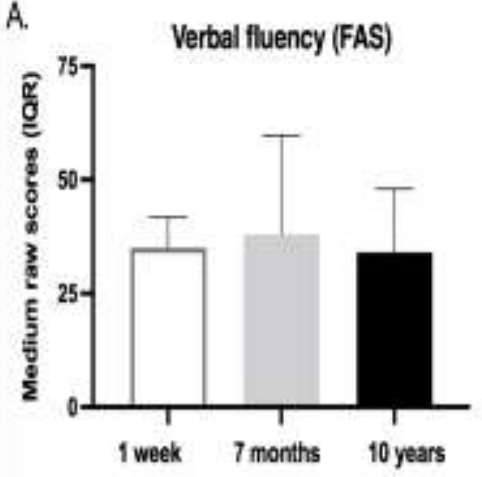

B.

Working memory (Digit span, backward)

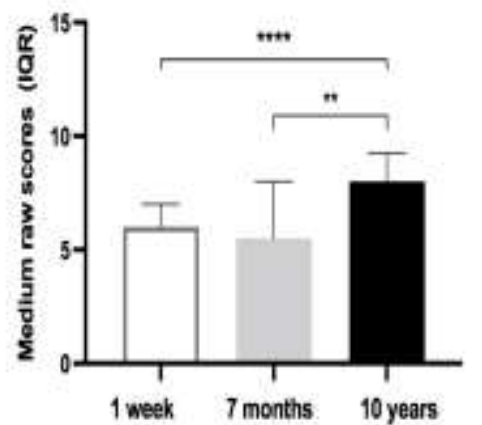

C.

Mental flexibility (TMT-B)

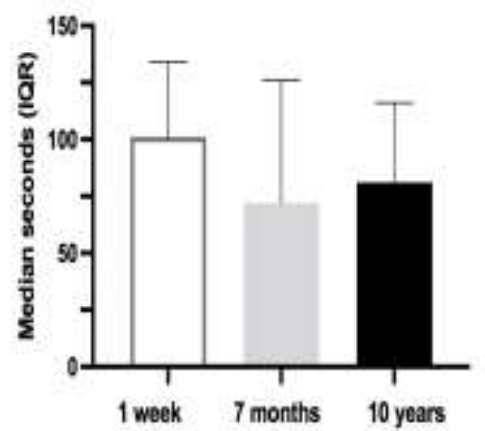

Kruskal-Wallis test with Dunn's multiple comparison test. ${ }^{* *} p<0.01$; $* * * p<0.0001$

Figure 1: Neuropsychological raw data on executive functioning over 10-year follow-ups after stroke onset.

Associations between subjective and objective EF

No significant association was found between patients perceived

\begin{tabular}{|l|c|c|c|}
\hline \multicolumn{1}{|c|}{ Executive functions } & FAS & $\begin{array}{c}\text { significant relationship with objective assessments of E } \\
\text { (backward) }\end{array}$ & TMT-B \\
\hline Global Executive Composite & & 0.16 & -0.02 \\
\hline Behavioural Regulation index & -0.07 & 0.20 & 0.03 \\
\hline Inhibit & -0.02 & 0.10 & 0.06 \\
\hline Shift & 0.15 & 0.18 & 0.04 \\
\hline Emotional control & -0.14 & 0.15 & -0.01 \\
\hline Self-monitor & -0.01 & 0.24 & -0.004 \\
\hline Metacognition Index & 0.09 & 0.12 & -0.05 \\
\hline Initiate & -0.13 & 0.13 & 0.06 \\
\hline Working memory & -0.14 & 0.11 & -0.21 \\
\hline Plan/Organize & -0.11 & -0.03 & 0.07 \\
\hline Task Monitor & -0.19 & 0.09 & -0.11 \\
\hline Organization of materials & -0.15 & 0.12 & 0.10 \\
\hline
\end{tabular}

No significant correlation was observed.

executive dysfunction and any of the tests of executive function (Table 3). Similarly, informant ratings of executive function didn't show any
significant relationship with objective assessments of EF (Table 4).

Table 3: Correlations between patients' BRIEF-A and FAS, Digit span (backward) and TMT-B.

\begin{tabular}{|l|c|c|c|}
\hline \multicolumn{1}{|c|}{ Executive functions } & FAS & $\begin{array}{c}\text { Digital span } \\
\text { (backward) }\end{array}$ & TMT-B \\
\hline Global Executive Composite & -0.23 & -0.10 & 0.16 \\
\hline Behavioural Regulation index & -0.07 & -0.04 & 0.15 \\
\hline Inhibit & 0.04 & -0.02 & 0.23 \\
\hline Shift & -0.26 & -0.13 & 0.05 \\
\hline Emotional control & -0.08 & -0.12 & 0.13 \\
\hline Self-monitor & 0.01 & 0.05 & 0.27 \\
\hline Metacognition Index & -0.28 & -0.17 & 0.09 \\
\hline Initiate & -0.29 & -0.06 & 0.03 \\
\hline Working memory & -0.22 & -0.17 & 0.05 \\
\hline Plan/Organize & $-0,23$ & 0.01 & 0.07 \\
\hline Task Monitor & -0.19 & -0.14 & 0.09 \\
\hline Organization of materials & -0.18 & -0.27 & 0.35 \\
\hline
\end{tabular}

No significant correlation was observed. 


\section{Discussion}

This study aimed to investigate EF among patients at 10-year after stroke onset through comparing subjective patients' and informants' perceptions of EF as well as objective assessments of EF. We found that patient and informant reported EF similarly on a group level, but more patients reported clinically significant executive dysfunctions than their informants did. Mismatches were observed between the patient and informant ratings of the BRIEF-A. Digit span backward was the only executive test that demonstrated significant improvement of EF at 10-year post-stroke in the cohort. However, performance-based EF tests did not demonstrate any significant association with patient nor informant ratings on EF.

Our data presented only subtle executive dysfunction in the participants from both patient and informant ratings on EF, which is congruent with highly independence in daily living reported by the participants. More patients reported clinically significant executive dysfunctions than their informants did. This may suggest that perceived executive dysfunction by patients is not always noticed by their relatives. The current results are also in line with many early studies where discrepancies between patientand informant-reported EF impairments were demonstrated among patients with dementia or traumatic brain injury $[10,15,16]$.

Among three performance-based executive tests, Digit span backward assessing working memory was the only test that demonstrated significant improvement over 10-year post-stroke in the cohort. No significant alteration was observed on mental flexibility (TMT-B) and verbal fluency (FAS) over 10-year follow-up. The reason for these discrepancies on NPA results are not fully understood but the tests measure different aspects of executive function located in different parts of the frontal lobes [21]. One possible explanation is that working memory, but not mental flexibility and verbal fluency, could be trained by active daily living $[1,2]$. This is supported by the finding that more than $90 \%$ of participants in the cohort were independent in their daily activities. Another possible reason is that verbal fluency and TMT-B, unlike Digit span, have a time aspect as part of the test $[9,19]$. This time pressure could make it more difficult for the patient. Furthermore, higher education level among the participants has in a previous study predicted better improvement of working memory, but not mental flexibility or verbal fluency (unpublished data [22]); and in this study a majority had more than 12 years of education.

Neither patient nor informant ratings on EF showed any significant association with objective performance-based EF tests in the study. The very small, non-significant correlations observed in the current study suggested that these three different tests should not be considered equal nor be used interchangeably [10]. Our results were consistent with many previous studies among patients with acquired brain injury or dementia [14-16] but not all [10]. The BRIEF-A provides a more complex, integrated and dynamic information on EF in the daily living [13] while NPA detects specific EF domains in a well-controlled standardized condition [9]. They may thus provide certain complementary information on EF. The clinical implication of the present findings may suggest that persons with stroke need both subjective and objective assessments on executive dysfunction due to its complex nature. It is necessary to performed these assessments in a large amount of stroke patients over a long-term follow-up to confirmation the generalisability of the current findings; and to enhance the knowledge of executive dysfunction after stroke.

The strength of the current study was the very long-term follow-up duration with repeated objective EF assessments at acute, sub-acute, and chronic phases over ten years after stroke onset. However, we are aware of the small number of participants as one of the limitations. Furthermore, stroke characteristics, such as stroke location and size, were not taken into account in the data analysis even though stroke severity is an important predictor of outcomes $[23,24]$. This is why it is not possible to generalize the findings to the entire young stroke population. Nevertheless, the current study provided some interesting insights into subjective and objective EF assessments.

\section{Conclusions}

We demonstrated that mis-match patient-informant agreement on perceived executive dysfunction showed no clear association with EF test performance in this study. This may indicate the complexity of EF among persons with stroke at chronic phase. Both subjective and objective assessment might provide certain complementary information on EF. A large-scale study is needed to confirm the generalisability of the current findings among stroke patients.

\section{Acknowledgments}

The authors would like to thank each participant and assessor for their patience and time. We also wish to acknowledge rehabilitation coordinator Catharina Elback for her excellent recruitment work.

This study was supported by the Västerbotten County Council and Umeå University (ALF Foundation), the Swedish Stroke Foundation (Stroke Riksförbundet) and the Northern Swedish Stroke Fund (Strokeforskning i Norrland Insamlingsstiftelse).

\section{Declaration of interest statement}

The authors report no conflicts of interest.

\section{References}

1. Poulin V, Korner-Bitensky N, Dawson DR, Bherer L. Efficacy of executive function interventions after stroke: A systematic review. Top Stroke Rehabil. 2012;19:158-171

2. Elgh E, Hu X. Dynamic trajectory of long-term cognitive improvement up to 10 years in young community-dwelling stroke survivors: A cohort study. Front Neurol. 2019;10:97

3. Zinn S, Bosworth HB, Hoenig HM, Swartzwelder HS. Executive function deficits in acute stroke. Arch Phys Med Rehabil. 2007;88:173-180

4. Tarantino V, Burgio F, Toffano R, Rigon E, Meneghello F, Weis L, Vallesi A. Efficacy of a training on executive functions in potentiating rehabilitation effects in stroke patients. Brain Sci. $2021 ; 11$

5. Schaapsmeerders P, Maaijwee NA, van Dijk EJ, Rutten-Jacobs LC, Arntz RM, Schoonderwaldt HC, Dorresteijn LD, Kessels RP, de Leeuw FE. Long-term cognitive impairment after firstever ischemic stroke in young adults. Stroke. 2013;44:16211628

6. Aam S, Einstad MS, Munthe-Kaas R, Lydersen S, Ihle-Hansen H, Knapskog AB, Ellekjaer H, Seljeseth Y, Saltvedt I. Poststroke cognitive impairment-impact of follow-up time and stroke subtype on severity and cognitive profile: The nor-coast study. Front Neurol. 2020;11:699

7. Shin M, Sohn MK, Lee J, Kim DY, Lee SG, Shin YI, Oh GJ, Lee YS, Joo MC, Han EY, Han J, Ahn J, Chang WH, Shin MA, Choi JY, Kang SH, Kim Y, Kim YH. Effect of cognitive reserve on risk of cognitive impairment and recovery after stroke: The kosco study. Stroke. 2020;51:99-107

8. Delis D, Kaplan E, Kramer J. D-kefs: Examiner's manual. San Antonio, TX: The Psychological Corporation; 2001.

9. Weschler D. Wais-iv: Weschler adult intelligence scale - fourth edition. Manual del 1, swedish version. Stockholm: NCS Pearson, Inc. ; 2010.

10. Toplak ME, West RF, Stanovich KE. Practitioner review: Do performance-based measures and ratings of executive function 
assess the same construct? J Child Psychol Psychiatry. 2013;54:131-143

11. Conti J, Sterr A, Brucki SM, Conforto AB. Diversity of approaches in assessment of executive functions in stroke: Limited evidence? eNeurologicalSci. 2015;1:12-20

12. Griffen JA, Rapport LJ, Bryer RC, Bieliauskas LA, Burt C. Awareness of deficits and on-road driving performance. Clin Neuropsychol. 2011;25:1158-1178

13. Roth R, Isquith $\mathrm{P}$, Gioia G. Behavior rating inventory of executive function - adult version: Professional manual. Lutz:: Psychological Assessment Resources; 2005.

14. Lanni KE, Ross JM, Higginson CI, Dressler EM, Sigvardt KA, Zhang L, Malhado-Chang N, Disbrow EA. Perceived and performance-based executive dysfunction in parkinson's disease. J Clin Exp Neuropsychol. 2014;36:342-355

15. Rabin LA, Wang C, Katz MJ, Derby CA, Buschke H, Lipton RB. Predicting alzheimer's disease: Neuropsychological tests, self-reports, and informant reports of cognitive difficulties. J Am Geriatr Soc. 2012;60:1128-1134

16. van der Linden SD, Gehring K, De Baene W, Emons WHM, Rutten GM, Sitskoorn MM. Assessment of executive functioning in patients with meningioma and low-grade glioma: A comparison of self-report, proxy-report, and test performance. J Int Neuropsychol Soc. 2020;26:187-196
17. Elgh E, Hu X. Visuospatial function at sub-acute phase predicts fatigue 10 years after stroke. Front Neurol. 2020;11:562706

18. Tulsky D, Zhu J, Ledbetter MF. Wais-iii/wms-iii technical manual. San Antonio, TX: Psychological Corporation; 1997.

19. Mitrushina M, Boone KB, Razani J, D'Elia LF. Handbook of normative data for neuropsychological assessment. Oxford University Press; 2005.

20. Cohen J. Statistical power analysis for the behavioral sciences (2nd ed.). Hillsdale, NJ: Lawrence Erlbaum Associates; 1988.

21. Lezak M, Howieson D, Bigler E, Tranel D. Neuropsychological assessment (5th ed.). New York: Oxford University Press.; 2012.

22. Elgh $\mathrm{E}, \mathrm{Hu} \mathrm{X}$. Higher education predicts improvement in working memory ten years after stroke onset Journal of Rehabilitation Medicine - Clinical Communications 2021:Under revision

23. Kogan E, Twyman K, Heap J, Milentijevic D, Lin JH, Alberts M. Assessing stroke severity using electronic health record data: A machine learning approach. BMC Med Inform Decis Mak. 2020;20:8

24. Rost NS, Bottle A, Lee JM, Randall M, Middleton S, Shaw L, Thijs V, Rinkel GJ, Hemmen TM, Global Comparators Stroke Gc. Stroke severity is a crucial predictor of outcome: An international prospective validation study. J Am Heart Assoc. $2016 ; 5$
This work is licensed under Creative Commons Attribution 4.0 License
Ready to submit your research? Choose Auctores and benefit from:

$>$ fast, convenient online submission

$>$ rigorous peer review by experienced research in your field

$>$ rapid publication on acceptance

$>$ authors retain copyrights

$>$ unique DOI for all articles

$>$ immediate, unrestricted online access

At Auctores, research is always in progress.

Learn more https://auctoresonline.org/journals/neuroscience-and-neurologicalsurgery 